\title{
New Buildings at University College, Nottingham.
}

A $\mathrm{S}$ already announced in NATURE, the new build$\mathrm{A}^{\mathrm{i}}$ ings of University College, Nottingham, are being opened by their Majesties the King and Queen on July 10. They form a worthy monument to Sir Jesse Boot, by whose generosity they have been provided. They occupy a good position in the new University Park, and provide ample accommodation for a large Arts Department, for four of the main branches of science, and for the Department of Pharmacy; they also include a large assembly hall, a library, a refectory fitted with all modern requirements, and commodious common rooms for men and women students.

\section{Chemistry Departuent.}

The Chemistry Department forms a ' $\mathrm{T}$ ' shaped building and, with the exception of the basement stores and a room for large scale operations, comprises two floors. In planning it two very important considerations have been kept in mind: first, that the main laboratories should be amply supplied with daylight and means of ventilation; and secondly, that the service store-room should be centrally placed and easily accessible from all parts. In accordance with these requirements four of the main laboratories are lighted both from above and from side windows and their walls are of white glazed tiles; drqught is provided for fume chambers and fume hoods on the working benches by means of numerous fans; with these arrangements it would seem that even at busy times the atmosphere of the laboratories will not be unpleasant. The service and supply stores are centrally situated on the main floor, the former opening directly into the largest laboratory and being very conveni-

ently placed for all the other important rooms. The main laboratory will accommodate about 80 students at one time; opening out of it are two smaller rooms, one of which is for physical chemistry. On the same floor there is another large laboratory for inorganic work, a lecture theatre which seats about a hundred, and a class room with accommodation for about forty students; lecture experiments for the theatre and class room will be got ready in an adjoining preparation room. The professor's room and chemistry staff room are also on this floor.

The principal laboratory for organic chemistry, with working places for about thirty students, is on the floor above. Adjoining it are the professor's laboratory and other small laboratories, followed by the Chemistry Museum-for minerals and specimens, and ending with a joint departmental library for physics and chemistry. Each of the three larger laboratories has its own balance room leading out of it.

\section{Physics Department.}

The Physics Department is compact, the most frequented rooms being connected by short passages or stairs. The rooms are arranged thus: Workshop on ground floor; lecture rooms, teaching laboratories, and store rooms on the first floor; research laboratories and professor's room and staff room on the second floor. The lecture theatre contains about one hundred seats, the steps of the seating rising from the lecture table on the isacoustic principle. The lecture lanterns are placed in front of the lecture tables and the screen is above the lecturer, so that lantern experiments and slides can be seen by the audience to the greatest advantage. The laboratory teaching is done in four large rooms, of which the largest has a floor space of $72 \mathrm{ft}$. by $36 \mathrm{ft}$. Steady tables are obtained by fixing them either on basement walls or on outer walls of the building. The circuit supplies to all laboratories and lecture rooms include direct and alternating high tension current, low tension current by bare copper rods, gas, water, steam, compressed air and exhaust. The research rooms are four in

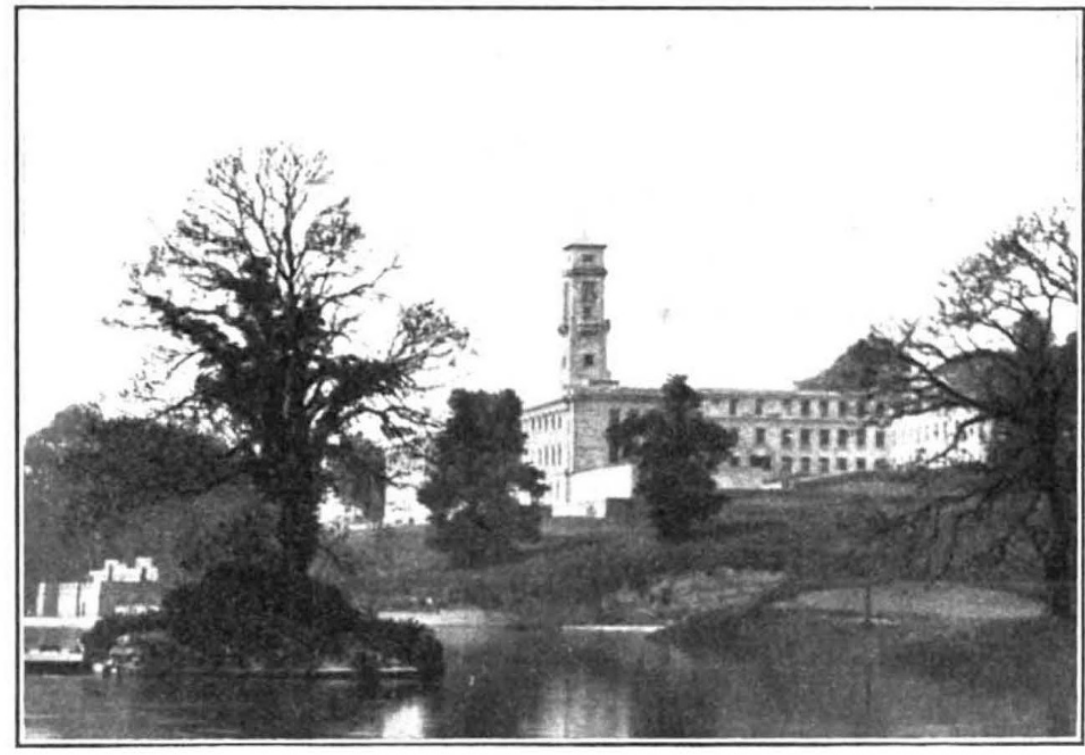

number, the largest having an area of $44 \mathrm{ft}$. by $28 \mathrm{ft}$. The workshop floor space, in two rooms, is $54 \mathrm{ft}$. by $25 \mathrm{ft}$. In order to protect the rooms above from vibration and noise from the machinery in the workshop, the shafting is carried, not on the ceiling of the workshop, but on a girder frame in the room, attached to the basement floor. The equipment includes four lathes, one of which is a Lorch-Schmidt, milling, shaping, and several drilling machines. A heavy lift connects the three floors of the department.

The accommodation in this department should suffice comfortably for, say, 150 undergraduates and future post-graduate research students, as well as for research by members of the staff.

\section{Biology Department.}

The Department of Biology comprises a lecture room accommodating about eighty students and three main laboratories. Of these, the general laboratory, which will be used both by botany and zoology students, contains fifty-four working places, each fitted with a microscope cupboard and a drawer for books and instruments. The advanced laboratory will be used by senior botany students

No. 3062, VoL. 122] 
(including post-graduates) and accommodates thirty workers. The third main laboratory is equipped for bacteriology, its fittings including a large culturecabinet for the storage of stock cultures. A dark room and photomicrographic equipment is attached to this laboratory. Small research laboratories are provided for the head of the Department and members of the staff.

In addition to the laboratories there is a teaching museum, the long window case of which is convertible into a working bench. Senior zoology students will work here, and provision has also been made for the storatge and study of medicinal plants and specimens. A plot of land has been set aside for experimental field studies and plant houses in the grounds behind the department.

\section{Department of Geology and Geocrraphy.}

The Department of Geology and Geography occupies the ground floor in the back western wing of the new buildings. It is compactly arranged and is self-contained with an entrance of its own. Two large elementary laboratories are provided for geology and geography respectively. A third spacious laboratory is set aside for the combined use by advanced students in both subjects. In each of these rooms there will be the usual work benches and tracing tables, together with adequate drawer accommodation for those geological collections which are in most frequent use and for maps of all kinds. There will also be glass-fronted wall cases for the exhibition of teaching series. The museum will be similarly equipped for the preservation and demonstration of more valuable exhibits. A room with seating accommodation for nearly forty students has been set aside for lecture purposes, whilst a suite of smaller rooms is being furnished for such purposes as staff research laboratories, classroom, preparation room, darkroom, and store room. A wide corridor, which connects all these rooms, will be fitted with additional show cases, and with cupboards for the storage of wall maps.

\section{Pharmacy Department.}

The Pharmacy Department consists of a large dispensary, a class room, and a model manufacturing laboratory, and shares with the Biology Department a laboratory-museum for pharmacognosy. The manufacturing laboratory is fitted with steam-heated copper pans, vacuum and fractionating stills, ovens, etc., and electrically-driven drug grinding machinery. An enclosed portion of this laboratory is devoted to apparatus used in testing, such as a polarimeter, refractometer, microscopes, and balances.

\section{The Aurora and its Spectrum. ${ }^{1}$}

THE two outstanding features that characterise the spectrum of the polar aurora are a set of four well-marked bands belonging to the first negative group of nitrogen, and a strongly defined very narrow spectral line in the green, the wave-length of which, measured by Babcock with a Fabry and Perot interferometer, was found to be $5577 \cdot 35 \pm 0 \cdot 005 \mathrm{~A}$. Less important features are a set of bands belonging to the second positive group of nitrogen and a miscellaneous, and as yet unidentified, set of sixteen lines or narrow bands. The auroral green line, the identity of which was for long unknown, was shown in 1925 by McLennan and Shrum to originate in gaseous atomic oxygen. This spectral line exhibits great variations in intensity with changing conditions of excitation. Helium and neon when mixed in excess with oxygen enhance the intensity of the line. Argon does the same thing, but to a much greater extent. In 1927, MeLennan and McLeod established the identity of the oxygen green line with the auroral green line beyond question, through obtaining $5577 \cdot 341 \mathrm{~A} . \pm 0.004 \mathrm{~A}$. for the wavelength of the former by the use of a Fabry and Perot interferometer.

The region in which auroræ generally occur in the upper atmosphere has for its lower boundary a height of approximately $80 \mathrm{~km}$, and for its upper limit a height of more than $400 \mathrm{~km}$. Auroræ occur with greatest frequency and brilliance at a height of $98 \mathrm{~km}$., but they have been observed so high as $1000 \mathrm{~km}$. It follows, then, that oxygen and nitrogen must be constituents of the earth's atmosphere up to these great heights. Through the work of Campbell, Lord Rayleigh, Slipher, and others, it is now known that on any clear night in any latitude, the whole sky is glowing with a faint green light, which is monochromatic and has the same wave-length as the 'green line' of the polar aurora. While the polar aurora appears to be excited by streams of electrons emitted by the sun from time to time, the green light of the non-polar aurora appears to originate through the action of some other agent.

The presence of the first negative bands of nitrogen

1 Abstract of the Bakerian Lecture delivered by Prof. J. C. McLennan, F.R.S., before the Royal Society on June 28 . in the spectrum of the aurora connotes an 'excitation potential' of $19 \cdot 6$ volts, while the absence of any nitrogen bands in the spectrum of the non-polar aurora imposes an upper limit of $12 \cdot 6$ volts for the "excitation potential' of the oxygen-auroral green line. With such 'excitation potentials' applied to oxygen, the only wave-lengths, with two doubtful exceptions, other than $\lambda 5577 \cdot 341$, known to originate in atomic oxygen, that could be emitted, lie too far in the ultra-violet or in the infra-red to appear in spectrograms taken hitherto of the auroral light.

The theoretical spectral term scheme formulated for atomic oxygen provides for two low metastable states, namely, ${ }^{1} S_{0}$ and ${ }^{1} D_{2}$, in addition to the normal ${ }^{3} \vec{P}_{01}$ levels. The recent work by Bowen on spectra of nebulæ makes it clear that so-called 'metastable states' are but states of long mean life, and that provided the gases involved are at a sufficiently low density, one may expect emission of radiation, corresponding to transitions between levels ordinarily designated as metastable. In such transitions it will be noted that the electronic azimuthal quantumnumber selection rules must necessarily be violated.

Under similar density conditions it is clear, from Bowen's work, that transitions are to be expected in which the inner quantum number selection rules also may be violated. In an investigation recently carried out by McLennan, McLeod, and Ruedy, photographs were obtained with a powerful echelon spectrograph of the magnetically resolved components of the auroral green line. The structure was shown to be that of a normal Zeeman triplet, and this result, combined with other evidence available, goes to show that the transition ${ }^{1} S_{0} \rightarrow{ }^{1} D_{2}$ is the one that gives rise to the auroral green line.

In an attempt to learn something of the agent responsible for the emission of the auroral green light from clear night sky, several series of observations were recently made by McLennan, McLeod, and Ireton, on the intensity of light received from the zenith in the course of a single night. In this investigation two lines of procedure were followed. In the one case several spectrographs of high light power were constructed and used to photograph the green line at 